\title{
Vazão de projeto na microdrenagem em locais sem dados de precipitação: estudo para o Rio Grande do Sul
}

\author{
Microdrainge design flow in ungaged basins: Rio Grande \\ do Sul, Brazil
}

\section{Raviel Eurico Basso \\ Daniel Gustavo Allasia \\ Rutinéia Tassi}

\section{Resumo}

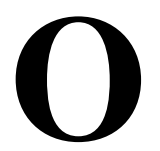

dimensionamento de estruturas da drenagem pluvial urbana é realizado, normalmente, a partir de dados de chuvas intensas. Essas informações comumente são obtidas por meio das relações intensidade-duração-frequência (IDF), ou na indisponibilidade destas, mediante metodologias simplificadas, tais como as relações entre durações, isozonas de chuvas, ou métodos sintéticos tais como os propostos por Bell (1969) e Chen (1983). Neste artigo é apresentada uma análise da aplicabilidade do método sugerido por Bell, com uma modificação (BACK, 2009), para estimativa de chuvas intensas no Estado do Rio Grande do Sul a partir de informações de chuva diárias, e o uso destas para a determinação de vazões utilizadas no dimensionamento de obras de microdrenagem. Os resultados mostraram que a metodologia de Bell e a modificada segundo Back (2009) estimaram corretamente as chuvas intensas e as vazões de microdrenagem (por sua vez estimadas a partir do método racional) para durações inferiores a 2 horas, quando comparada com informações obtidas diretamente de equações IDFs, em que as variações médias ficaram próximas a 10\%. As exceções foram em Espumoso e em Santa Vitória do Palmar, onde superaram os 15\% de variação, o que a torna uma opção adequada para o dimensionamento de estruturas da microdrenagem pluvial, quando as relações IDF não estiverem disponíveis.

Palavras-chave: Bell. Drenagem. Precipitação intensa. Vazão de projeto.

\section{Abstract}

${ }^{1}$ Raviel Eurico Basso ${ }^{1}$ Universidade Federal de Santa Maria Santa Maria - RS - Brasil

${ }^{2}$ Daniel Gustavo Allasia ${ }^{2}$ Universidade Federal de Santa Maria Santa Maria - RS - Brasil

${ }^{3}$ Rutinéia Tassi ${ }^{3}$ Universidade Federal de Santa Maria Santa Maria - RS - Brasil

Recebido em 25/07/18 Aceito em 16/09/18
The design of urban drainage facilities is normally based on intense rainfall data. This data is usually obtained through the intensity-duration-frequency (IDF) relationships or, when they are unavailable, by means of simplified methodologies such as nested intensities, isozones, or synthetic methods such as those proposed by Bell (1969) and Chen (1983). This paper presents an analysis of the applicability of Bell's (1969) method, with a modification proposed by Back (2009), to estimate intense rainfall in the state of Rio Grande do Sul, and its use in microdrainage design. The results show what the modified Bell methodology is able to correctly estimate intense rainfall and flows (estimated by the rational formula) with a duration lower than 2 hours, where average variations were close to 10\%. The exceptions were in Espumoso and Santa Vitória do Palmar, where the variation was over 15\%, which makes the methodology an adequate option for the design of microdrainage facilities when IDFs are unavailable.

Keywords: Bell. Drainage. Intense rainfall. Design flow. 


\section{Introdução}

Na hidrologia, as chuvas intensas são aquelas que geram grandes vazões em um intervalo de tempo relativamente curto, e são utilizadas como um valor crítico em projetos de drenagem (BERTONI; TUCCI, 1993; DINGMAN, 2002; ENDRENY; IMBEAH, 2009; KOUTSOYIANNIS; KOZONIS; MANETAS, 1998; REED; FAULKNER; STEWART, 1999; VIEIRA; NETO; SANTOS, 1998). Geralmente as informações de chuvas intensas são obtidas a partir das relações IDF, que representam de forma simples a intensidade máxima de chuva que poderá ocorrer com certa duração e frequência, associada a uma discretização temporal, normalmente de uns poucos minutos.

Dada a sua importância em projetos de drenagem, as relações IDF deveriam estar sempre atualizadas e disponíveis em um banco de dados acessível e simples, para que os profissionais da área tenham livre acesso. No entanto, a determinação das relações IDF é dependente da disponibilidade de dados pluviográficos, com discretização temporal pequena ( $<10 \mathrm{~min}-20 \mathrm{~min})$, com longos períodos de observação ( $>20$ anos) e com poucas falhas, condições que resultam em poucas relações IDF disponíveis no Brasil (BASSO et al., 2016; PACHALY et al., 2017).

Comparativamente com os demais estados da Federação Brasileira, o Rio Grande do Sul (RS) possui um número considerável de estações de monitoramento pluviográfico (BELTRAME; LANNA; LOUZADA, 1991), embora muito aquém das recomendações da Organização Meteorológica Mundial (ORGANIZAÇÃO..., 2008). Ainda, a maior parte dessas estações possui períodos de observação relativamente curtos e com muitas falhas, dificultando, ou mesmo impedindo, a utilização desses dados para a determinação da IDF local. Dessa forma, a disponibilidade de relações IDF no RS é restrita a alguns locais e, em muitos casos, com informações desatualizadas (BERNARDI et al., 2015).

Por outro lado, no RS existem informações de precipitação com discretização temporal normalmente não utilizada na construção de relações IDF de forma direta, tais como dados diários disponíveis no Banco de Dados Meteorológicos para Ensino e Pesquisa (BDMEP), mantido pelo Instituto Nacional de Meteorologia (INMET), no Sistema de Informações Hidrológicas da Agencia Nacional de Águas (HidroWeb - ANA) e de estações instaladas por outros órgãos ou instituições (ex.: Companhia Estadual de Energia Elétrica - CEEE; Fundação
Estadual de Pesquisa Agropecuária - FEPAGRO, etc.). Além dos dados diários, existem algumas estações automáticas do Instituto Nacional de Pesquisas Espaciais (INPE) com discretização horária, porém a série de dados está disponível apenas para períodos mais recentes.

Nesse cenário, são necessárias novas abordagens metodológicas que permitam extrair dos dados existentes as informações necessárias para a estimativa de chuvas de projeto. Dentre as metodologias promissoras se encontra a apresentada por Bell (1969), que estabelece uma equação genérica para a relação IDF, com base em uma chuva local com duração de 1 hora e período de recorrência de 10 anos. Essa equação baseia-se no fato de que as chuvas intensas de curta duração são, geralmente, ocasionadas pelas chuvas convectivas, a qual possui um comportamento semelhante, independente da região de sua ocorrência no globo (BELL, 1969). Com isso, a aplicação da metodologia de Bell (1969) poderia ser a solução para o problema de escassez de dados de precipitação.

Dessa forma, neste artigo é analisada a aplicabilidade do método proposto por Bell (1969) no RS, incluindo a modificação de Back (2009) para a estimativa da precipitação intensa para o dimensionamento de estruturas na microdrenagem.

\section{Estimativas de precipitação em locais sem dados}

\section{Estudo de chuvas intensas realizado por Bell (1969)}

O principal objetivo do estudo realizado por Bell (1969) foi mostrar que as chuvas intensas de curta duração são causadas, geralmente, pelas chuvas convectivas, e apresentam características e ocorrências semelhantes em todo o mundo. Para comprovar sua hipótese, Bell (1969) utilizou como base os estudos realizados por Hershfield (1961) e Reich (1963), e analisou, em uma primeira etapa, as relações entre altura (lâmina precipitada) e diferentes durações $(\mathrm{t})$ para o mesmo período de recorrência (TR), que se constituem de relações empíricas recomendadas pelo U.S. Weather Bureau Technical Paper $\mathrm{N}^{\circ} 40$ (HERSHFIELD, 1961) (ou também conhecidas como relações entre durações (BERTONI; TUCCI, 1993)). Assim, Bell (1969) estimou as precipitações intensas com duração de $5 \mathrm{~min}, 10 \mathrm{~min}, 15 \mathrm{~min}, 30 \mathrm{~min}$ e $2 \mathrm{~h}$, relacionando-as com a precipitação intensa com duração de 1 hora. 
Bell (1969) verificou pouca variabilidade nas relações entre precipitações para todo o território dos Estados Unidos, independentemente do TR utilizado na análise. Quando esses resultados foram comparados com os obtidos na ex-União Soviética, Austrália e África do Sul, observaram-se valores semelhantes. Com base nisso, Bell (1969) determinou primeiramente a Equação 1, conhecida como relação entre durações, que representa a relação entre a altura de precipitação (P) com duração (t) para durações entre 5 min e $120 \mathrm{~min}$ $\left(\mathrm{P}_{\mathrm{t}}^{\mathrm{TR}}\right)$, e a precipitação de $1 \mathrm{~h}\left(\mathrm{P}_{60}^{\mathrm{TR}}\right)$.

$\frac{P_{0}^{M R}}{P_{E 0}^{M R}}=0,54 t^{0,25}-0,50$

Eq. 1

Onde:

$P_{\mathbb{I}}^{T R} / P_{60}^{T R}$ a relação entre a lâmina de chuva (mm) e duração da precipitação (t) em minutos, com TR em anos, onde $5 \min \leq \mathrm{t} \leq 120 \mathrm{~min}$; e

Em termos práticos, conhecida a precipitação de 1 h de duração, pode ser estimada a precipitação com qualquer duração, para um TR dado.

Posteriormente, Bell (1969) analisou as relações altura-frequência de precipitações de diferentes TR e mesma duração. Comparando as relações das chuvas com TR de 1, 2, 5, 25, 50 e 100 anos, com a precipitação com período de recorrência de 10 anos como referência e, ainda, as de TR de 25 e 100 anos em relação à chuva de 2 anos de TR, para vários lugares, como Estados Unidos (incluindo Havaí e Alasca), Austrália, África do Sul e Porto Rico, foram verificadas tendências semelhantes para todos esses locais. Assim, Bell (1969) propôs a Equação 2 para a relação entre altura (lâmina de precipitação) e frequência de ocorrência, limitando a sua aplicação para os períodos de recorrência entre 2 e 100 anos. Em outras palavras, conhecida a precipitação com TR de 10 anos e uma duração qualquer, pode ser estimada a precipitação com a mesma duração e qualquer TR.

$\frac{P_{\mathrm{P}}^{\mathrm{MR}}}{P_{\mathrm{E}}^{\mathrm{SO}}}=0,21 . \ln T R+0,52$

Eq. 2

Onde $\mathrm{P}_{\mathrm{t}}^{\mathbb{T R}} \mathrm{P}_{\mathrm{t}}^{10}$ a relação entre altura-frequência da precipitação com TR anos e t minutos, com relação à chuva da mesma duração e 10 anos de período de recorrência.

A combinação das Equações 1 e 2 resulta na Equação 3, que permite obter a relação alturaduração-frequência para precipitações intensas com duração de até 2 horas e TR menores que 100 anos, baseado unicamente em informações da precipitação de TR de 10 anos e 1 h de duração.

$P_{t}^{T R}=(0,21 \cdot \ln T R+0,52) \cdot\left(0,54 \cdot t^{0,25}-\right.$ $0,50) \cdot P_{60}^{10}$

Eq. 3
Onde:

$P_{t}^{T R}=$ precipitação com TR anos e duração de $\mathrm{t}$ minutos; e

$P_{60}^{10}=$ precipitação com 10 anos de período de recorrência e duração de 60 min; e

$\mathrm{TR}=$ período de recorrência em anos, onde 2 anos $\leq \mathrm{TR} \leq 100$ anos; $\mathrm{e}$

$\mathrm{t}=$ duração em minutos, onde $5 \mathrm{~min} \leq \mathrm{t} \leq 120 \mathrm{~min}$.

Uma vantagem na aplicação do método de Bell (1969), em relação à IDF, é o menor requerimento de dados. No entanto, o próprio Bell (1969) observou que para diversos locais a determinação da precipitação com uma duração de 60 min não seria possível, uma vez que a informação disponível normalmente é obtida em pluviômetros (dados diários). Assim, determinou-se fórmulas empíricas (Equações 4 e 5) com base na informação diária para a obtenção da $\mathbb{P}_{60}^{10}$ (STEPHENSON, 1981).

$\begin{array}{ll}P_{60}^{10}=0,27 \cdot M \cdot N^{0,9 a} \quad(0<M \leq 50) & \text { Eq. } 4 \\ P_{60}^{10}=0,97 \cdot M^{0,67} \cdot N^{0,3 a}(50<M \leq 115) & \text { Eq. } 5\end{array}$

Onde:

$\mathrm{P}_{60}^{10}=$ precipitação com 10 anos de TR e duração de $60 \mathrm{~min}$;

M = média das precipitações máximas diárias em $\mathrm{mm}$; e

$\mathrm{N}$ = número médio anual de dias com chuva $(1<\mathrm{N}$ $<80)$.

Para os locais com séries relativamente curtas, Bell (1969) determinou uma equação baseada na precipitação intensa com duração de 60 min e período de recorrência de 2 anos para a obtenção da precipitação intensa (Equação 6) para diferentes TR, o que permite obter a precipitação com TR de 10 anos.

$P_{t}^{T R}=(0,35 . \ln T R+0,76)\left(0,54 . t^{0,25}-\right.$ $0,50) \cdot P_{60}^{2}$

Eq. 6

Onde:

$\mathrm{P}_{\mathrm{t}}^{\mathrm{TR}}=$ precipitação com TR em anos e duração de $\mathrm{t}$ em minutos;

$\mathrm{P}_{60}^{2}=$ precipitação com 2 anos de período de recorrência e duração de 60 minutos; e

$\mathrm{TR}$ = período de recorrência em anos.

A equação é válida para 2 anos $\leq \mathrm{TR} \leq 100$ anos e 5 minutos $\leq \mathrm{t} \leq 120$ minutos.

Diversos autores realizaram análises da equação de Bell (1969) e testaram sua confiabilidade para diversos locais, como Medan e Sumatra na 
Indonésia (WILD; HALL, 1982), Maputo em Moçambique (DEUTSCHE..., 1981), Yundum Airport em Banjul na Gambia (TOWNSEND, 1977). Pode-se destacar também estudos realizados no Brasil, como por exemplo os de Back (2009), Genovez, Zuffo e Borri Genovez (1994), Uehara et al. (1980), Falaguasta e Genovez (2003), Genovez e Zuffo (2000), entre outros.

\section{Variações da equação de Bell (1969)}

A metodologia apresentada por Bell (1969) foi adaptada e utilizada como base em diferentes estudos (CHEN, 1983; FROEHLICH, 1995; UEAHARA et al., 1980; BACK, 2009; RIGHETTO, 1998; COUTINHO et al., 2011), em diferentes países, na estimativa das precipitações intensas.

Chen (1983) desenvolveu, a partir da metodologia utilizada por Bell (1969), uma fórmula generalizada de IDF que utiliza três alturas de precipitação: $P_{1}^{10}$ (chuva com duração de $1 \mathrm{~h}$ e tempo de recorrência de 10 anos), $P_{24}^{10}$ (chuva com duração de 24 h e tempo de recorrência de 10 anos) e $P_{1}^{100}$ (chuva com duração de $1 \mathrm{~h}$ e tempo de recorrência de 100 anos).

Com o emprego destas alturas, Chen (1983) passou a considerar variações na chuva intensa, devido à posição geográfica, as quais Bell (1969) não considerou em seu estudo. A Equação 7, proposta por Chen (1983), demonstrou que as precipitações estimadas pela Equação 3, com duração superior a 2 h, apresentam grandes variações em relação aos dados observados, confirmando a não adequação da equação generalizada de Bell (1969) para duração superior a 2 h, conforme recomendação do próprio autor.

$P_{t}^{T R}=\frac{a_{1} P_{1}^{10} \log \left\{10^{2-x}\left[\ln \left(\frac{T R}{T R-1}\right)\right]^{-[(x-1)}\right\}}{\left(t+b_{1}\right)^{c_{1}}} \cdot\left(\frac{t}{60}\right)$

Eq. 7

Onde:

$a_{1}, b_{1}, c_{1}=$ parâmetros de chuva que podem ser obtidos de forma gráfica na publicação de Chen (1983);

$\mathrm{P}_{\mathrm{t}}^{\mathrm{TR}}=$ precipitação com $\mathrm{TR}$ anos de período de recorrência e duração de t minutos;

$\mathbf{P}_{1}^{10}=$ precipitação com 10 anos de período de recorrência e duração de 1 h;

TR = período de recorrência em anos e t a duração em minutos; e

$\mathrm{x}=$ relação entre a $\mathrm{P}_{\mathrm{t}}^{100} / \mathrm{P}_{\mathrm{t}}^{10}$.

Froehlich (1995), apresentou uma modificação da equação apresentada por Chen (1983), para estimar as precipitações com duração intermediária (entre
$1 \mathrm{~h}$ e $24 \mathrm{~h})$ para qualquer local no centro e leste dos Estados Unidos, Alaska, Havaí, Porto Rico e Ilhas Virgens Americanas, com base nos mapas de isoietas disponibilizados pelo Nathional Weather Service (NWS). Os parâmetros são determinados conforme a distribuição estatística dos dados extremos, com equações para quatro tipos de distribuição (tipo I, II, III e IV). No estudo, foi definida de forma simples uma equação que fornece boas estimativas de precipitações intensas com duração entre $1 \mathrm{~h}$ e $24 \mathrm{~h}$, semelhante àquela previamente proposta por Bell (1969) e Chen (1983).

Fahmi et al. (2005 ${ }^{1}$ apud SOLIMAN, 2010), propuseram uma modificação da equação de Bell (1969) para regiões áridas (Equação 8).

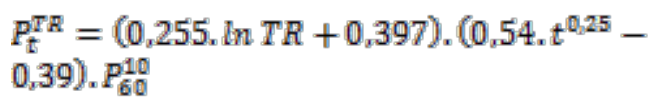

Eq. 8

Onde:

$\mathbb{P}_{t}^{\text {TR }}=$ precipitação com TR anos de período de recorrência e duração de t minutos;

$\mathrm{P}_{60}^{10}=$ precipitação com 10 anos de período de recorrência e duração de $60 \mathrm{~min}$;

$\mathrm{TR}=$ período de recorrência em anos, onde 2 anos $\leq \mathrm{TR} \leq 100$ anos; e

$\mathrm{t}=$ duração em minutos, onde $5 \min \leq \mathrm{t} \leq 120 \mathrm{~min}$.

Ueahara et al. (1980), utilizando a mesma metodologia proposta por Bell (1969), propuseram uma relação altura-duração-frequência para todo o Brasil (Equação 9), e uma específica para o estado de SP (Equação 10), utilizando dados de 26 postos pluviográficos com no mínimo 25 anos de observação.

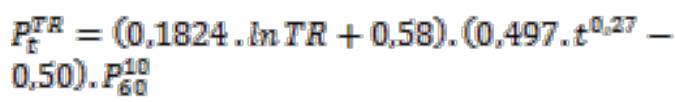

Eq. 9

$P_{t}^{T R}=(0,22 \cdot \ln T R+0,50) \cdot\left(0,38 \cdot t^{0,31}-\right.$

$0,39) \cdot P_{60}^{10}$

Eq. 10

Onde:

$\mathbb{P}_{\mathrm{t}}^{\mathrm{TR}}=$ precipitação com TR anos de período de recorrência e duração de t minutos;

$\mathrm{P}_{60}^{10}=$ precipitação com 10 anos de período de recorrência e duração de $60 \mathrm{~min}$;

${ }^{1}$ FAHMI, A. H. et al. Generalized Depth Duration Frequency Relationship in Arid Regions. In: INTERNATIONAL SYMPOSIUM ON ENVIRONMENTAL HYDROLOGY IN ARID AND SEMI-ARID REGION, 4., Cairo, 2005. Proceedings... Cairo, 2005. 
TR = período de recorrência em anos, onde 2 anos $\leq \mathrm{TR} \leq 100$ anos; e

$\mathrm{t}=$ duração em minutos, onde $5 \min \leq \mathrm{t} \leq 120 \mathrm{~min}$.

Back (2009) ajustou a equação de Bell (1969), tendo como base a chuva máxima com duração de 1 dia, e período de recorrência de 10 anos, que relacionam as precipitações com diferentes durações aos dados do município de Urussanga, no estado de Santa Catarina. Assim, o autor propôs uma modificação na Equação 3, com a qual é possível obter a altura máxima da chuva com uma duração qualquer e um período de recorrência de até 100 anos (Equação 11).

$P_{t}^{T R}=(a \cdot \ln T R+b) \cdot\left(c \cdot t^{d}-e\right) \cdot P_{d i a}^{10} \quad$ Eq. 11

Onde:

a, b, c, d, e = coeficientes empíricos;

$\mathbb{P}_{t}^{\text {TR }}=$ precipitação com $\mathrm{TR}$ anos de período de recorrência e duração de $t$ minutos;

$\mathbb{P}_{\text {dia }}^{10}=$ precipitação com 10 anos de período de recorrência e duração de 1 dia;

$\mathrm{TR}=$ período de recorrência em anos; e

$\mathrm{t}$ = duração em minutos.

Righetto (1998) apresentou uma equação similar à Equação 11 para o Brasil, porém a $\mathbb{P}_{\text {dia }}^{10}$ foi substituída pela precipitação com 2 anos de período de recorrência e uma duração de 1 hora $\left(\mathrm{P}_{1 \mathrm{~h}}^{2}\right)$, propondo a sua determinação por meio dos dados pluviométricos, em conjunto com os coeficientes de desagregação determinados pelo DAEE/CETESB (DEPARTAMENTO..., 1980).

Coutinho et al. (2011) ajustaram a equação de Bell (1969), apresentada por Righetto (1998), para as estações pluviométricas do estado do Mato Grosso, por meio das relações entre durações apresentadas por DAEE/CETESB (DEPARTAMENTO..., 1980). No entanto, não conseguiram determinar uma equação regional, pois as equações ajustadas apresentaram grande variabilidade, e superestimaram as chuvas intensas obtidas a partir das relações entre durações.

\section{Materiais e métodos}

A análise da aplicabilidade do método sugerido por Bell (1969), com uma modificação (BACK, 2009), para a estimativa de chuvas intensas no estado do Rio Grande do Sul, e o uso destas para a determinação das vazões utilizadas no dimensionamento de redes de microdrenagem pluvial foi realizada em duas etapas. Na primeira etapa, as precipitações intensas estimadas pela metodologia de Bell (1969) foram comparadas com as precipitações obtidas a partir de outras fontes, tais como as relações IDF. Na segunda etapa, as vazões estimadas pelo método racional (KUICHLING, 1889) foram utilizadas na comparação, para avaliar a qualidade dos resultados, em razão das fontes de dados de precipitação (Bell, IDF e relação entre durações). O método racional foi apresentado pela primeira vez em 1851 por Mulvaney e aprimorado em 1889 por Kuichling (KUICHLING, 1889). Foi escolhido por ser o método mais utilizado em projetos de microdrenagem no Brasil (BIDONE; TUCCI, 1995) e no exterior, apesar das limitações conhecidas do método.

As etapas metodológicas são descritas com maior detalhe na sequência.

\section{Seleção dos dados}

Foram selecionados locais com informação de chuva intensas no RS, tais como relações IDF ou locais que possuem relações entre durações apresentados por Beltrame, Lanna e Louzada (1991) (Figura 1 e Tabela 1). Essas metodologias permitem estimar as precipitações intensas utilizadas normalmente em projetos de microdrenagem, e servem de comparação da qualidade das estimativas com a metodologia de Bell (1969). Para alguns locais com relações IDF conhecidas, mas sem relação entre durações, foram utilizados para fins de comparação os coeficientes de desagregação de chuvas intensas apresentados por Basso et al. (2016). Dados diários também foram selecionados de estações pluviométricas coincidentes com os locais com chuvas intensas (Tabela 1), para posterior aplicação da metodologia modificada de Bell proposta por Back (2009).

Foram utilizadas as relações IDF mais recentes, e eliminadas as informações repetidas, IDF baseadas na mesma informação, obtidas por meio de relações entre durações genéricas, tais como as apresentadas em DAEE/CETESB (DEPARTAMENTO..., 1980) ou Tucci (1993).

\section{Estimativa de vazão com uso do método racional}

Após a seleção dos dados de chuva, o método racional (Equação 12) foi aplicado para a estimativa da vazão em bacias de drenagem fictícias, para fins investigativos, mas que possuem características típicas das áreas urbanas com redes de microdrenagem, ou mesmo de áreas rurais, nas quais normalmente são instaladas obras de drenagem como condutos, bueiros, entre outros.

$Q=0,278 . C \cdot L A$

Eq. 12 
Onde:

$\mathrm{Q}=$ vazão de pico gerada em $\mathrm{m}^{3} . \mathrm{s}^{-1}$;

$\mathrm{C}=$ coeficiente de escoamento superficial;

$\mathrm{I}=$ intensidade da chuva em $\mathrm{mm} \cdot \mathrm{h}^{-1}$; e

$\mathrm{A}$ = área da bacia de drenagem em quilômetros quadrados.

As bacias de drenagem utilizadas possuem área superficial de: $0,5 \mathrm{~km}^{2}, 1,0 \mathrm{~km}^{2}, 1,5 \mathrm{~km}^{2}$ e 2,0 km². Com relação às características topográficas, foram consideradas duas situações possíveis:

(a) bacias de cabeceira, em locais de grande velocidade, com declividade de 0,06 m.m-1; e

(b) bacias típicas de regiões mais planas, com declividade inferior a 0,001 m.m-1, em um total de 8 diferentes bacias.

Dessa forma, para as bacias mais declivosas, com maior velocidade de escoamento, foram determinados os tempos de concentração (tc) de $13,6 \mathrm{~min}, 16,8 \mathrm{~min}, 19,1 \mathrm{~min}$ e $20,8 \mathrm{~min}$, para as áreas de $0,5 \mathrm{~km}^{2}$, 1,0 km², 1,5 km² e 2,0 km², respectivamente, obtidos através da metodologia de Kirpich (KIRPICH, 1940). Para a situação de bacias mais planas, foram arbitrados os tempos 30 min, 60 min, 90 min e 120 min para as áreas de 0,5 $\mathrm{km}^{2}, 1,0 \mathrm{~km}^{2}, 1,5 \mathrm{~km}^{2}$, e $2,0 \mathrm{~km}^{2}$, respectivamente. A referência da intensidade da precipitação foi obtida com base nas relações IDF (bacias declivosas e planas) e nas relações entre durações (bacias planas).

Também foi adotado o coeficiente de escoamento superficial do método racional (Equação 12), de 0,78 para considerar uma área densamente urbanizada (área impermeável de aproximadamente 80\%). Valores diferentes do coeficiente foram investigados, no entanto não mostraram diferenças nos resultados.

\section{Aplicação da metodologia de Bell (1969)}

A aplicação da Equação 3 requer somente o conhecimento da precipitação com 1 h de duração e TR de 10 anos $\left(\mathrm{P}_{60}^{10}\right)$. Essa precipitação foi obtida por meio das relações IDF, ou de dados pluviométricos em conjunto com os coeficientes de desagregação da precipitação apresentados por Beltrame, Lanna e Louzada (1991) e Basso et al. (2016).

\section{Figura 1 - Locais selecionados para o estudo}

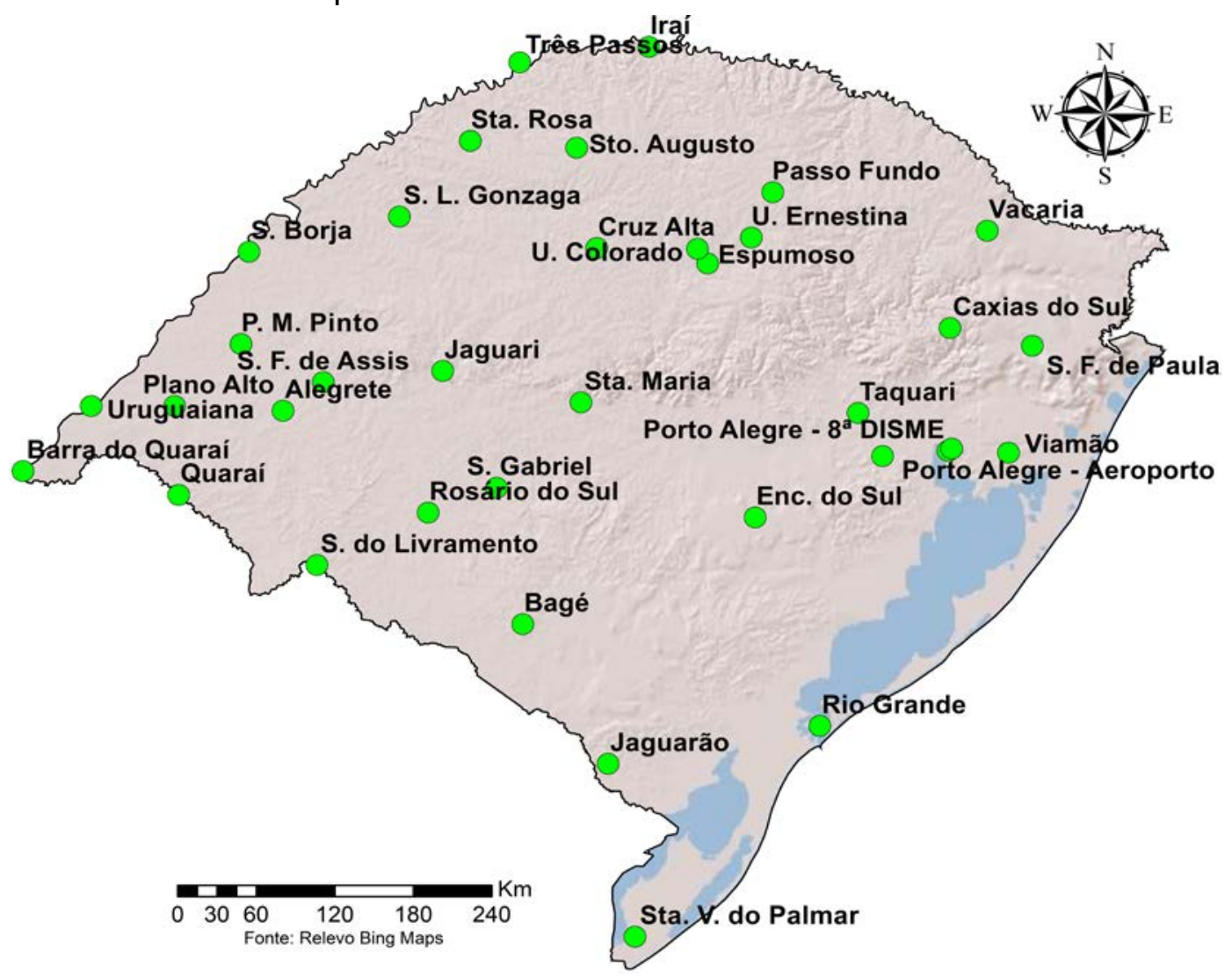

238 Basso, R. E.; Allasia, D. G.; Tassi, R. 
Tabela 1 - Locais selecionados para o desenvolvimento do estudo

\begin{tabular}{|c|c|c|c|c|c|}
\hline Locais selecionados & $\begin{array}{l}\text { Estação } \\
\text { Código } \\
\text { ANA* }\end{array}$ & Início & Fim & $\begin{array}{c}\text { Relação entre } \\
\text { durações* } \\
\text { (BELTRAME; } \\
\text { LANNA; } \\
\text { LOUZADA, 1991) } \\
\end{array}$ & IDF* \\
\hline Alegrete & 02955001 & 1952 & 1970 & $\mathrm{X}$ & $\mathrm{X}$ \\
\hline Bagé & 03154001 & 1912 & 1998 & $\mathrm{X}$ & $\mathrm{X}$ \\
\hline Barra do Quaraí & 03057002 & 1977 & 1989 & $\mathrm{X}$ & \\
\hline Caxias do Sul & 02951008 & 1912 & 1977 & $\mathrm{X}$ & $\mathrm{X}$ \\
\hline Cruz Alta & 02853005 & 1939 & 1967 & $\mathrm{X}$ & $\mathrm{X}$ \\
\hline Encruzilhada do Sul & 03052005 & 1914 & 1942 & $\mathrm{X}$ & $\mathrm{X}$ \\
\hline Espumoso & 02852012 & 1951 & 1967 & $\mathrm{X}$ & \\
\hline Guaíba Country Club & 03051005 & 1970 & 2006 & $\mathrm{X}$ & \\
\hline Iraí & 02753003 & 1939 & 1968 & $\mathrm{X}$ & $\mathrm{X}$ \\
\hline Jaguarão & 03253007 & 1967 & 1980 & $\mathrm{X}$ & \\
\hline Jaguari & 02954007 & 1958 & 2006 & $\mathrm{X}$ & \\
\hline Passo Fundo & 02852020 & 1916 & 1970 & $\mathrm{X}$ & $\mathrm{X}$ \\
\hline Passo Mariano Pinto (Alegrete) & 02956006 & 1970 & 1991 & $\mathrm{X}$ & \\
\hline Plano Alto (Uruguaiana) & 02956007 & 1944 & 1990 & $\mathrm{X}$ & \\
\hline Porto Alegre ( $8^{\circ}$ DISME) & 03051011 & 1961 & 2012 & $\mathrm{X}$ & $\mathrm{X}$ \\
\hline Quaraí & 03056003 & 1960 & 1976 & $\mathrm{X}$ & \\
\hline Rio Grande & 03252024 & 1985 & 2006 & $\mathrm{X}$ & $\mathrm{X}$ \\
\hline Rosário do Sul & 03054016 & 1977 & 2006 & $\mathrm{X}$ & \\
\hline Santa Maria & 02953017 & 1939 & 1966 & $\mathrm{X}$ & $\mathrm{X}$ \\
\hline Santa Rosa & 02754005 & 1953 & 1966 & $\mathrm{X}$ & \\
\hline Santa Vitória do Palmar & 03353007 & 1936 & 1970 & $\mathrm{X}$ & $\mathrm{X}$ \\
\hline Santana do Livramento & 03055001 & 1913 & 1961 & $\mathrm{X}$ & \\
\hline Santo Augusto & 02753007 & 1948 & 1981 & $\mathrm{X}$ & \\
\hline São Borja & 02856003 & 1939 & 1965 & $\mathrm{X}$ & \\
\hline São Francisco de Assis & 02955008 & 1977 & 2008 & $\mathrm{X}$ & \\
\hline São Francisco de Paula & 02950032 & 1912 & 1961 & $\mathrm{X}$ & \\
\hline São Gabriel & 03054010 & 1950 & 1978 & $\mathrm{X}$ & \\
\hline São Luiz Gonzaga & 02854011 & 1916 & 1970 & $\mathrm{X}$ & $\mathrm{X}$ \\
\hline Taquari & 02951030 & 1932 & 1966 & $\mathrm{X}$ & \\
\hline Três Passos & 02754001 & 1950 & 2006 & $\mathrm{X}$ & \\
\hline Uruguaiana & 02957001 & 1912 & 1978 & $\mathrm{X}$ & $\mathrm{X}$ \\
\hline Usina Colorado (Tapera) & 02852029 & 1959 & 1982 & $\mathrm{X}$ & \\
\hline Usina Ernestina (Passo Fundo) & 02852030 & 1943 & 1982 & $\mathrm{X}$ & \\
\hline Vacaria & 02850011 & 1915 & 1965 & $\mathrm{X}$ & \\
\hline Viamão & 03050006 & 1939 & 1948 & $X$ & $X$ \\
\hline
\end{tabular}

Nota: Legenda: *Agência Nacional de Águas; e

*X representa o tipo de informação disponível.

No caso específico da aplicação dos coeficientes de desagregação, foram obtidos os dados pluviométricos consistidos do site HidroWeb da Agência Nacional de Águas (ANA) para as estações apresentadas na Tabela 1. Primeiramente foram determinadas as precipitações máximas anuais com duração de 1 dia, por meio da metodologia de Gumbel (GRINGORTEN, 1970). A metodologia de Gumbel já foi aplicada com sucesso na região (SAMPAIO et al., 2011; BELTRAME; LANNA; LOUZADA, 1991; ELTZ; REICHERT; CASSOL, 1992); de qualquer forma, a aderência do ajuste foi verificada através dos testes de qui-quadrado, Kolmogorov-Smirnov e Anderson-Darling. Os dados diários foram desagregados com utilização dos coeficientes de desagregação, obtendo-se assim a $P_{60}^{10}$, necessária para a aplicação da metodologia de Bell (1969).

Na sequência foram estimadas as chuvas intensas com TR de 2, 5, 10, e 20 anos, e durações iguais aos tempos de concentração das bacias de drenagem avaliadas, com a utilização da Equação 3 , permitindo a posterior aplicação do método racional. 
Devido à grande quantidade de dados pluviométricos no estado do Rio Grande do Sul e à escassez de dados pluviográficos, foi realizado também o ajuste da Equação 11, modificada pelo método de Bell (1969), a fim de estimar as chuvas intensas a partir de dados diários. Esse procedimento evita a necessidade do uso da metodologia da relação entre durações para desagregar a chuva diária. Essa modificação já foi testada com sucesso por Back (2009) em Santa Catarina, e utiliza como precipitação de referência diretamente a precipitação diária, e não mais a de 1 $\mathrm{h}$ de duração.

No ajuste da Equação 11, é necessária a determinação de cinco parâmetros ( $a, b, c, d$ e $e$ ), com base na precipitação diária com tempo de retorno de 10 anos. Para calibração desses parâmetros, faz-se necessário conhecer a distribuição temporal da precipitação, com base nas estações pluviométricas, juntamente com as relações entre durações ou IDF. O ajuste dos parâmetros foi efetuado com auxílio da ferramenta computacional Curve Expert v1.37 (HYAMS, 2013), por meio de metodologias não lineares. Assim, comprovada a aplicabilidade das equações ajustadas, foram definidas regiões homogêneas do RS e os parâmetros regionais, o que possibilita a aplicação em futuros estudos.

\section{Resultados e discussão}

Inicialmente foram comparadas as precipitações intensas conhecidas por meio de IDF, ou obtidas com uso do coeficiente de desagregação, com o resultado da aplicação da Equação 3. Os resultados obtidos com a metodologia de Bell foram ligeiramente melhores quando comparados com as IDF (Figura 2), em relação àqueles obtidos com base nos coeficientes de desagregação "R" (Figura 3). As Figuras 2 e 3 apresentam apenas os piores resultados obtidos. O desempenho inferior no caso do método da relação entre durações e Bell pode ser explicado em função do comportamento errático apresentado em alguns locais (ex.: Figura 3a - Espumoso e Figura 3d - Santo Augusto), podendo ser consequência de séries de precipitação (curtas e/ou com erros na medição). Roman et al. (2015), Bertoni e Tucci (1993) indicam que as séries de precipitação devem ser, pelo menos, 3 vezes mais extensas que o TR a ser estimado.

De qualquer forma, em termos gerais os resultados foram muito similares em todos os locais analisados, conforme apresentado na Tabela 2, que apresenta a variação média das precipitações com duração inferior a 2 h para diversos TR.

\section{Figura 2 - Comparação entre as precipitações estimadas pela equação de Bell e a IDF}

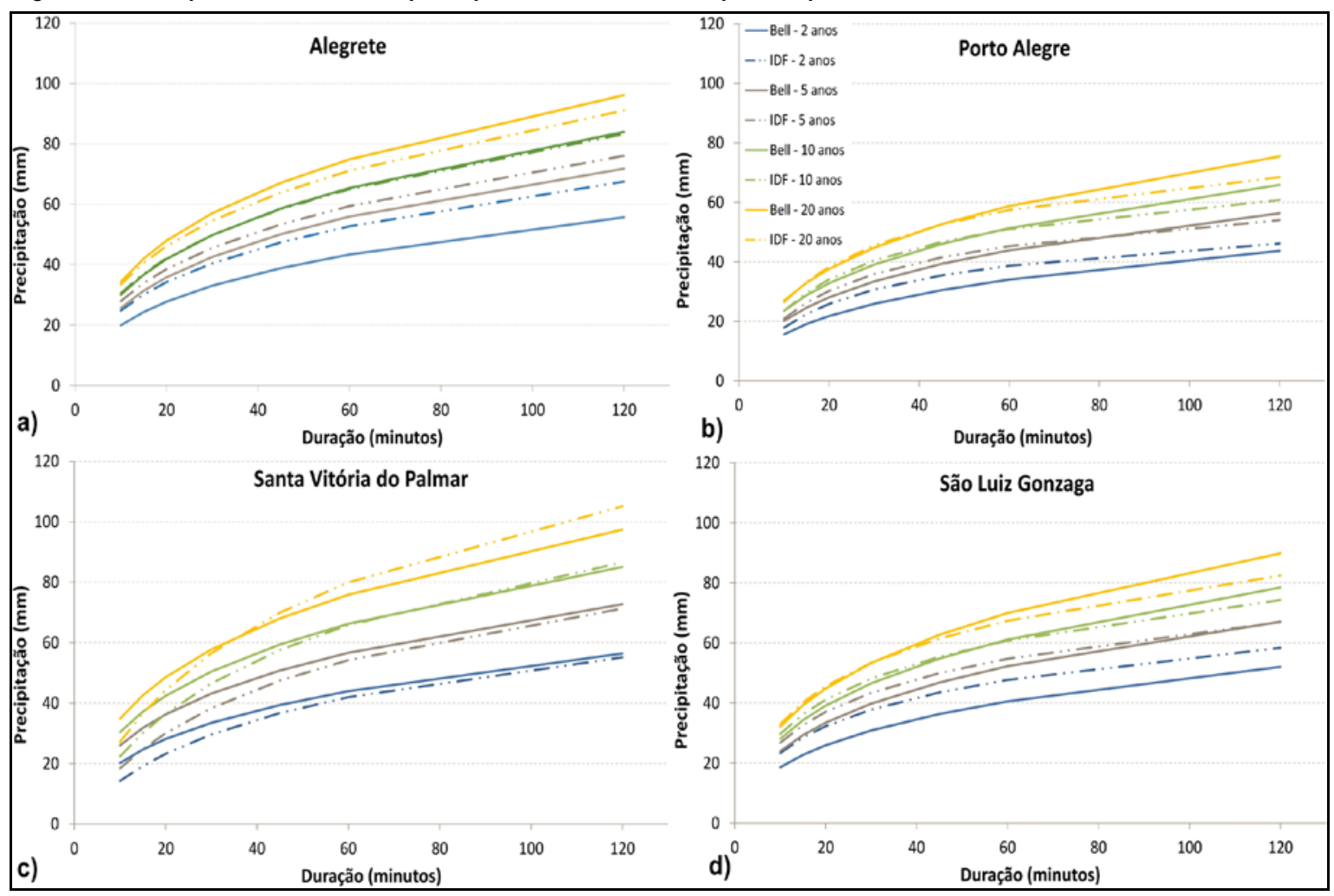

240 Basso, R. E.; Allasia, D. G.; Tassi, R. 
Figura 3 - Comparação entre as precipitações estimadas pela equação de Bell e as relações entre durações
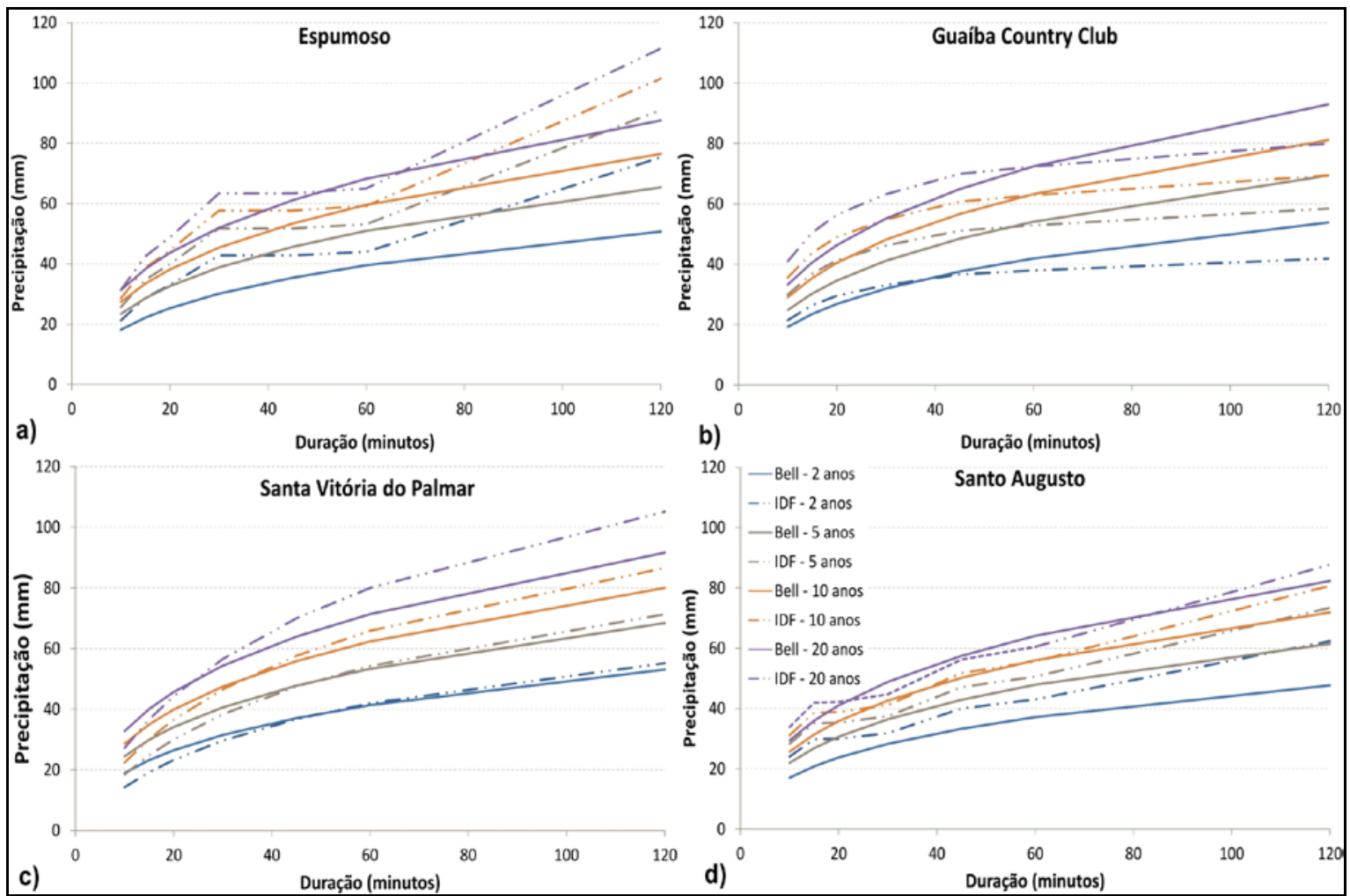

As maiores diferenças ocorreram para as precipitações com TR de 2 anos, como pode ser observado nos municípios de Alegrete (Figura 2a) e São Luiz Gonzaga (Figura 2d), com aproximadamente $20 \%$ de subestimativa, enquanto os resultados foram muito similares para os TR maiores (diferenças menores a 10\%) com exceção de Santa Vitória do Palmar (Figura 2c), onde há uma superestimativa máxima de aproximadamente 15\% nas precipitações com duração inferior a 30 min. A espacialização desses resultados pode ser observada na Figura 4, na qual estão apresentadas as variações médias para as durações de $30 \mathrm{~min}, 1$ h e 2 h. Esses três valores estão indicados na figura para cada localidade.

Na sequência, foram estimadas as vazões de escoamento superficial pelo método racional

(Equação 12). As estatísticas descritivas dessa análise estão apresentadas na Tabela 3, na qual é possível observar a comparação das vazões obtidas com base em Bell (1969) com as vazões obtidas com base nas relações IDF (bacias planas e declivosas) e relação entre durações (bacias planas). Com base nessa análise, identificou-se que as maiores diferenças ocorreram para as chuvas com TR de 2 anos, para todas as bacias de drenagem e tempos de concentração. As menores variações na estimativa das vazões foram para as bacias de drenagem intermediárias (área entre 1 $\mathrm{km}^{2}$ e $1,5 \mathrm{~km}^{2}$ ) para os TR superiores a 2 anos; com relação ao tempo de concentração (TC), a variação foi maior para menores TC. 
Figura 4 - Variação da precipitação obtida por Bell (1969) - a) comparação com a IDF, b) comparação com a relação entre durações

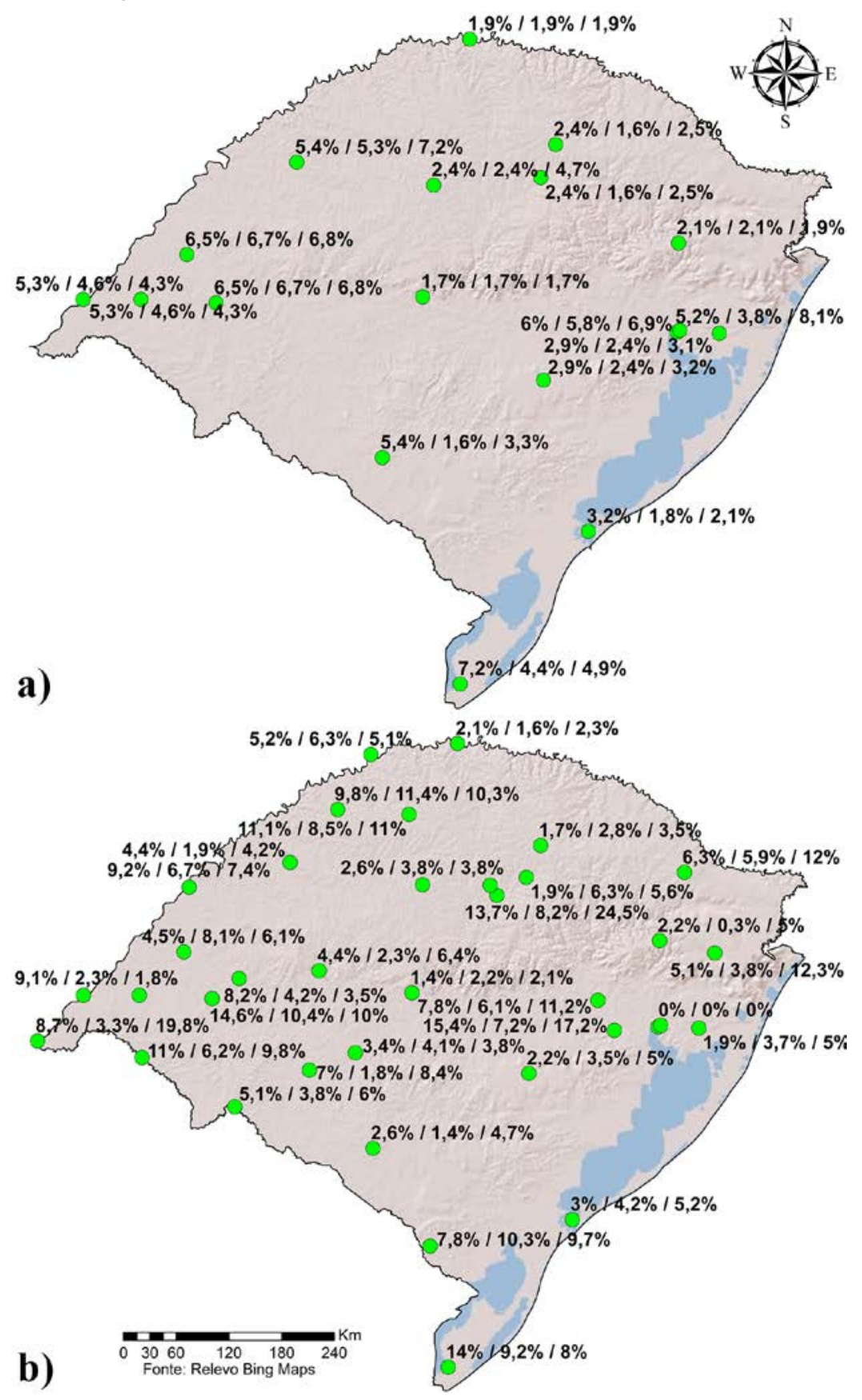


Tabela 2 - Diferença média em percentagem entre as precipitações intensas obtidas com a aplicação do método de Bell e as obtidas através das relações entre durações (Beltrame et al 1991) e IDF, para TR $2,5,10,15,20$ e 30 anos e $10 \mathrm{~min}<\mathrm{tc}<120 \mathrm{~min}$

\begin{tabular}{|c|c|c|}
\hline \multirow{2}{*}{ Locais selecionados } & \multicolumn{2}{|c|}{ Diferença (\%) } \\
\hline & Relação entre durações & Intensidade-duração-frequência \\
\hline Alegrete & 6,50 & 6,80 \\
\hline Bagé & 6,10 & 3,30 \\
\hline Barra do Quaraí & 9,40 & \\
\hline Caxias do Sul & 2,30 & 1,90 \\
\hline Cruz Alta & 3,40 & 4,70 \\
\hline Encruzilhada do Sul & 3,10 & 3,20 \\
\hline Espumoso & 13,30 & \\
\hline Guaíba Country Club & 12,70 & \\
\hline Iraí & 1,90 & 1,90 \\
\hline Jaguarão & 9,50 & \\
\hline Jaguari & 4,80 & \\
\hline Passo Fundo & 2,10 & 2,50 \\
\hline $\begin{array}{l}\text { Passo Mariano Pinto } \\
\text { (Alegrete) }\end{array}$ & 6,50 & \\
\hline Plano Alto (Uruguaiana) & 6,20 & \\
\hline Porto Alegre ( $8^{\circ}$ DISME) & 4,90 & 8,10 \\
\hline Quaraí & 10,00 & \\
\hline Rio Grande & 3,20 & 2,10 \\
\hline Rosário do Sul & 6,00 & \\
\hline Santa Maria & 1,80 & 1,70 \\
\hline Santa Rosa & 10,20 & \\
\hline Santa Vitória do Palmar & 12,90 & 4,90 \\
\hline Santana do Livramento & 4,40 & \\
\hline Santo Augusto & 10,90 & \\
\hline São Borja & 8,60 & \\
\hline São Francisco de Assis & 6,90 & \\
\hline São Francisco de Paula & 6,30 & \\
\hline São Gabriel & 4,00 & \\
\hline São Luiz Gonzaga & 4,30 & 7,20 \\
\hline Taquari & 8,20 & \\
\hline Três Passos & 5,30 & \\
\hline Uruguaiana & 6,20 & 4,30 \\
\hline Usina Colorado (Tapera) & 8,90 & \\
\hline Usina Ernestina (Passo Fundo) & 2,10 & \\
\hline Vacaria & 6,70 & \\
\hline Viamão & 2,90 & 3,10 \\
\hline
\end{tabular}


Tabela 3 - Estatística descritiva das vazões estimadas para as bacias de drenagem

\begin{tabular}{|c|c|c|c|c|c|c|c|c|c|c|}
\hline \multirow[b]{3}{*}{ Prec. } & \multirow{2}{*}{\multicolumn{2}{|c|}{$\begin{array}{c}\text { Bacia de } \\
\text { drenagem }\end{array}$}} & \multicolumn{8}{|c|}{ Tempo de recorrência (anos) } \\
\hline & & & \multicolumn{2}{|c|}{2} & \multicolumn{2}{|c|}{5} & \multicolumn{2}{|c|}{10} & \multicolumn{2}{|c|}{20} \\
\hline & $\begin{array}{c}\text { Áre } \\
\text { a } \\
\left(\mathrm{m}^{2}\right) \\
\end{array}$ & $\begin{array}{c}\mathrm{TC} \\
(\mathrm{min})\end{array}$ & $\begin{array}{l}\text { Var. } \\
|\%|\end{array}$ & Sd $|\%|$ & $\begin{array}{l}\text { Var. } \\
|\%|\end{array}$ & Sd $|\%|$ & $\begin{array}{l}\text { Var. } \\
|\%|\end{array}$ & $\begin{array}{c}\text { Sd } \\
|\%|\end{array}$ & $\begin{array}{l}\text { Var. } \\
|\%|\end{array}$ & $\begin{array}{c}\text { Sd } \\
|\%|\end{array}$ \\
\hline \multirow{8}{*}{ IDF } & 0,5 & 30 & 10,86 & 4,65 & 3,99 & 3,46 & 2,04 & 2,20 & 2,35 & 1,71 \\
\hline & 1 & 60 & 9,32 & 4,61 & 2,54 & 1,69 & 0,65 & 0,01 & 2,21 & 1,68 \\
\hline & 1,5 & 90 & 8,15 & 4,96 & 2,25 & 1,49 & 1,87 & 1,30 & 2,99 & 2,52 \\
\hline & 2 & 120 & 7,31 & 5,29 & 2,83 & 1,63 & 2,97 & 2,28 & 3,93 & 3,17 \\
\hline & 0,5 & 13,6 & 11,30 & 7,99 & 5,67 & 8,03 & 4,87 & 6,57 & 4,27 & 5,25 \\
\hline & 1 & 16,8 & 11,08 & 6,81 & 4,96 & 6,65 & 3,94 & 5,14 & 3,58 & 3,87 \\
\hline & 1,5 & 19,1 & 10,99 & 6,14 & 4,67 & 5,89 & 3,45 & 4,43 & 3,26 & 3,15 \\
\hline & 2 & 20,8 & 10,92 & 5,76 & 4,47 & 5,39 & 3,12 & 3,96 & 3,05 & 2,70 \\
\hline \multirow{4}{*}{$\begin{array}{l}\text { Relação } \\
\text { entre } \\
\text { durações }\end{array}$} & 0,5 & 30 & 8,72 & 6,18 & 5,37 & 5,23 & 3,99 & 5,04 & 5,44 & 4,88 \\
\hline & 1 & 45 & 7,59 & 5,29 & 4,20 & 3,22 & 2,94 & 3,19 & 4,47 & 3,97 \\
\hline & 1,5 & 60 & 6,91 & 5,83 & 2,72 & 1,62 & 0,65 & 0,02 & 3,59 & 2,00 \\
\hline & 2 & 120 & 10,43 & 10,01 & 7,94 & 6,93 & 8,29 & 6,19 & 9,36 & 6,34 \\
\hline
\end{tabular}

Nota: Legenda:

Prec. (precipitação);

IDF (intensidade-duração-frequência):

TC (tempo de concentração);

Var. (variação); e

Sd (desvio padrão).

De forma geral (Tabela 4), pode-se concluir que a estimativa das vazões com base na metodologia proposta por Bell (1969) teve erros médios entre $1,5 \%$ e $10 \%$ para todos os TR. A única exceção foi em Santa Vitória do Palmar, a qual superou os $20 \%$, quando comparada com a vazão estimada pelas relações IDF. Nas bacias mais planas o erro foi inferior a 7,5\% em todos os locais. Quando a vazão estimada com base na precipitação determinada pelo método de Bell é comparada com aquela obtida por meio das relações entre durações, a variação superou $10 \%$ apenas em 3 localidades (Barra do Quaraí, 11,42\%; Espumoso, 16,30\%; e Rio Grande, 12,48\%), o que possivelmente está relacionado às incertezas nos dados, em razão do tamanho da série. Para as bacias declivosas os resultados foram melhores, com diferenças menores a $9 \%$ em todos os locais (com exceção de Santa Vitória) para TR maiores a 2 anos.

Portanto, com base neste estudo, é possível afirmar que a equação proposta por Bell (1969), além de ser mais simples sua obtenção que uma relação IDF, produz estimativas confiáveis das precipitações intensas (erros menores a 10\% na maioria dos casos), podendo ser utilizada para a obtenção das vazões utilizadas nos projetos de microdrenagem, especialmente em locais sem dados.

Uma vez verificada a adequabilidade do método de Bell (1969) para a estimativa de precipitações intensas, foi realizado o ajustamento da Equação
11 (modificação de Back (2009)) para todos os 35 locais com conhecimento das precipitações intensas, pois ela mesma possibilita obter as precipitações intensas a partir de informações diárias $\left(\mathrm{P}_{\mathrm{dia}}^{10}\right)$, e apresenta um monitoramento mais amplo no RS. Assim, utilizando como base a semelhança entre os parâmetros ajustados da Equação 11 para cada local, e com o apoio dos mapas de Unidades Climáticas do Brasil apresentado por IBGE (INSTITUTO..., 1997), o Atlas Pluviométrico do Brasil (COMPANHIA..., 2011) e as regiões apresentadas por Rossato (2011), foi possível a determinação de 6 regiões homogêneas (Figura 5a), e seus respectivos parâmetros $(a, b, c, d$ e $e)$ para a equação de precipitação intensa regional (Tabela 5). A Figura $5 \mathrm{~b}$ apresenta, de forma espacial, o comportamento da precipitação $\mathbb{P}_{\text {dia }}^{10}$ necessária nas equações regionais.

Os resultados mostraram que a utilização das equações regionais propostas são eficientes na estimativa da precipitação de curta duração (até 2 h) a partir de dados diários, produzindo resultados similares àqueles obtidos com o emprego da equação original de Bell (1969), conforme se observa na Figura 6 (erros médios para durações de $30 \mathrm{~min} / 1 \mathrm{~h} / 2 \mathrm{~h}$ ). No entanto, em alguns locais aconteceram erros maiores: Viamão (39,0\%), Plano Alto (Uruguaiana) (30,7\%), Três Passos (25,8\%), Passo Fundo (20,8\%), Usina Colorado (Tapera) (18,9\%) e Uruguaiana (19,4\%), podendose creditar as diferenças ao tamanho da série ou até 
a diferenças na precipitação entre os locais. Silveira (1997), Silveira, Bemfica e Goldenfum (2000), Allasia e Villanueva (2007), Fensterseifer et al. (2013) e Favaretto (2016) mostraram que estações em Porto Alegre, mesmo a menos de 10 km umas das outras, podem apresentar diferenças de até $70 \%$ na intensidade da precipitação para o mesmo TR em função de efeitos associados com a urbanização e topografia na região.

Tabela 4 - Variação média da vazão gerada pelo método racional com base na equação de Bell (1969)

\begin{tabular}{|c|c|c|c|c|c|c|}
\hline \multirow{3}{*}{ Locais selecionados } & \multicolumn{4}{|c|}{ B. planas } & \multirow{2}{*}{\multicolumn{2}{|c|}{$\begin{array}{l}\text { B. declivosas } \\
\text { Comp. IDF }\end{array}$}} \\
\hline & \multicolumn{2}{|c|}{ Comp. Relação } & \multicolumn{2}{|c|}{ Comp. IDF } & & \\
\hline & $\left|\mathbf{m}^{3} / \mathbf{s}\right|$ & $|\%|$ & $\left|\mathbf{m}^{3} / \mathbf{s}\right|$ & $|\%|$ & $\left|\mathbf{m}^{3} / \mathbf{s}\right|$ & $|\%|$ \\
\hline Alegrete & 0,889 & 6,98 & 0,970 & 7,39 & 2,403 & 7,72 \\
\hline Bagé & 0,31 & 2,39 & 0,331 & 3,48 & 2,223 & 8,93 \\
\hline Barra do Quaraí & 1,637 & 11,42 & & & & \\
\hline Caxias do Sul & 0,356 & 2,80 & 0,187 & 1,65 & 0,462 & 1,86 \\
\hline Cruz Alta & 0,415 & 2,92 & 0,518 & 3,64 & 1,079 & 3,44 \\
\hline Encruzilhada do Sul & 0,412 & 2,76 & 0,308 & 3,51 & 0,750 & 3,46 \\
\hline Espumoso & 2,581 & 16,30 & & & & \\
\hline Guaíba Country Club & 1,275 & 9,69 & & & & \\
\hline Iraí & 0,713 & 5,20 & 0,256 & 2,51 & 0,625 & 2,52 \\
\hline Jaguarão & 0,966 & 8,86 & & & & \\
\hline Jaguari & 0,793 & 4,56 & & & & \\
\hline Passo Fundo & 0,58 & 4,58 & 0,224 & 2,45 & 0,440 & 2,12 \\
\hline $\begin{array}{l}\text { Passo Mariano Pinto } \\
\text { (Alegrete) }\end{array}$ & 1,463 & 8,00 & & & & \\
\hline Plano Alto (Uruguaiana) & 0,787 & 5,50 & & & & \\
\hline Porto Alegre ( $8^{\circ}$ DISME) & 0,357 & 2,78 & 0,612 & 5,93 & 1,663 & 6,66 \\
\hline Quaraí & 1,046 & 6,68 & & & & \\
\hline Rio Grande & 1,547 & 12,48 & 0,249 & 2,13 & 0,847 & 2,82 \\
\hline Rosário do Sul & 0,572 & 5,52 & & & & \\
\hline Santa Maria & 0,334 & 1,99 & 0,590 & 5,13 & 0,532 & 2,13 \\
\hline Santa Rosa & 0,584 & 3,96 & & & & \\
\hline Santa Vitória do Palmar & 0,364 & 3,14 & 0,611 & 4,86 & 4,975 & 20,47 \\
\hline Santana do Livramento & 0,504 & 3,63 & & & & \\
\hline Santo Augusto & 1,196 & 8,76 & & & & \\
\hline São Borja & 0,752 & 5,53 & & & & \\
\hline São Francisco de Assis & 0,901 & 6,72 & & & & \\
\hline São Francisco de Paula & 1,213 & 8,17 & & & & \\
\hline São Gabriel & 0,394 & 3,33 & & & & \\
\hline São Luiz Gonzaga & 0,322 & 1,75 & 0,790 & 6,53 & 2,741 & 9,23 \\
\hline Taquari & 0,814 & 6,51 & & & & \\
\hline Três Passos & 0,492 & 5,73 & & & & \\
\hline Uruguaiana & 0,25 & 1,26 & 0,603 & 5,34 & 1,686 & 6,16 \\
\hline Usina Colorado (Tapera) & 1,052 & 5,49 & & & & \\
\hline Usina Ernestina (Passo Fundo) & 0,807 & 5,64 & & & & \\
\hline Vacaria & 0,839 & 7,00 & & & & \\
\hline Viamão & 0,603 & 4,63 & 0,259 & 3,43 & 0,796 & 4,40 \\
\hline
\end{tabular}

Nota: Legenda:

B. (bacia);

Comp. (comparação);

IDF (intensidade-duração-frequência). 
Tabela 5 - Parâmetros ajustados para a equação proposta por Back (2009) para as 6 regiões homogêneas do RS, para os TR 2, 5, 10,15, 20 e 30 anos e $10<$ duração < 1.440 min

\begin{tabular}{c|c|c|c|c|c}
\hline \multirow{2}{*}{ Região } & \multicolumn{5}{|c}{ Parâmetros ajustados } \\
\cline { 2 - 6 } & a & b & c & d & e \\
\hline A & 0,191 & 0,628 & 0,178 & 0,259 & 0,124 \\
B & 0,179 & 0,543 & 0,882 & 0,123 & 0,902 \\
C & 0,324 & 1,059 & 0,640 & 0,095 & 0,664 \\
D & 0,387 & 1,322 & 0,129 & 0,225 & 0,130 \\
E & 0,185 & 0,523 & 0,330 & 0,211 & 0,333 \\
F & 0,732 & 2,956 & 0,230 & 0,108 & 0,256 \\
\hline
\end{tabular}

Figura 5 - (a) Regiões homogêneas, e (b) precipitação com TR de 10 anos e duração diária ( $P_{\text {dia }}^{10}$ )

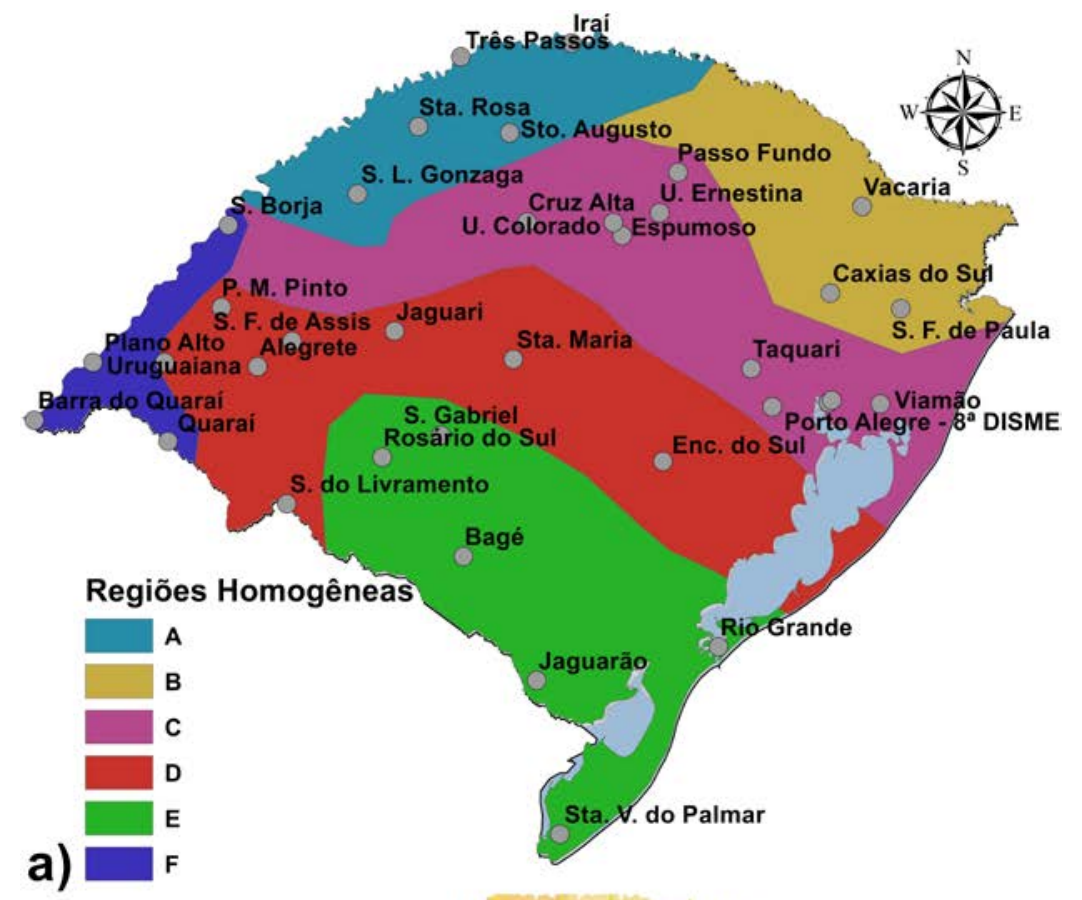

a) $\mathrm{F}$

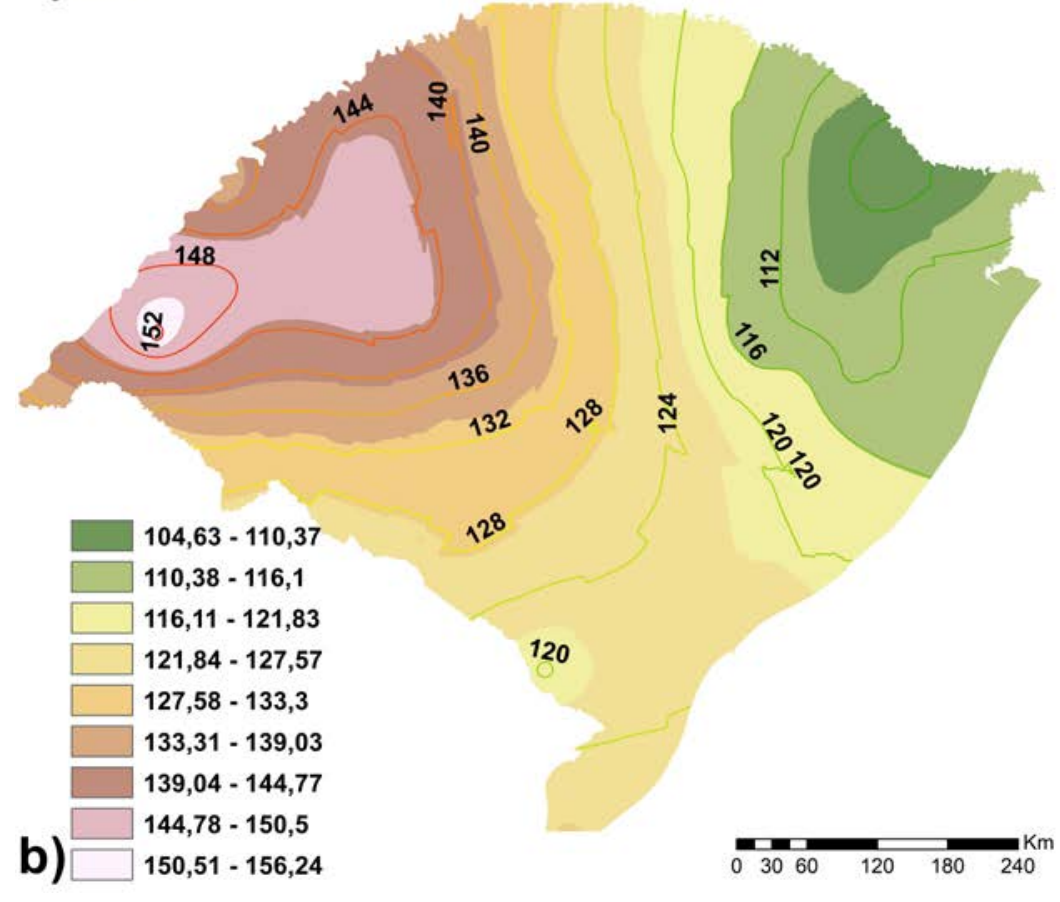

246 Basso, R. E.; Allasia, D. G.; Tassi, R. 
Figura 6 - Erro médio com base nas equações regionais, comparativamente à relação IDF e à relação entre durações para a estimativa da precipitação intensa

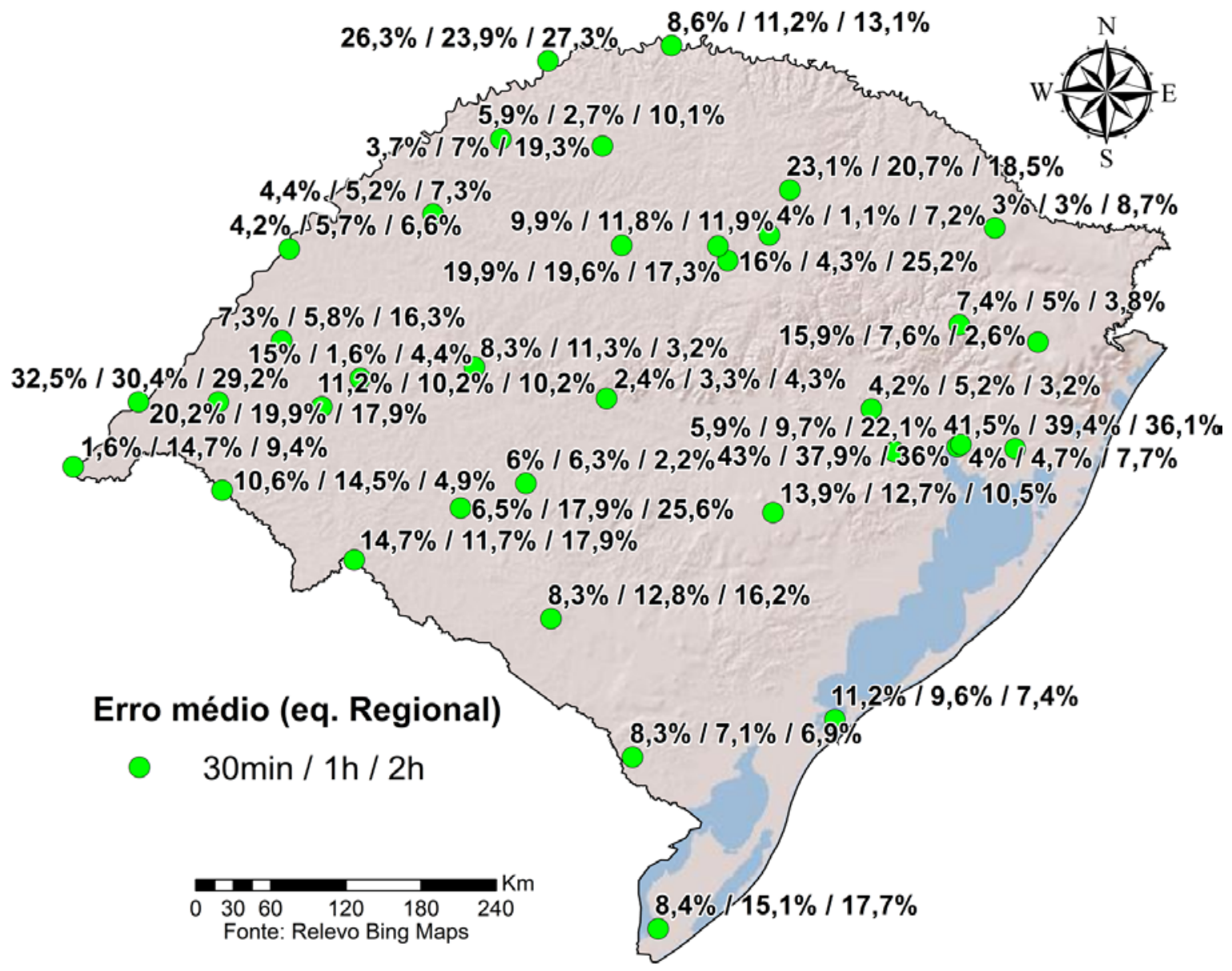

\section{Conclusão}

O Rio Grande do Sul, a exemplo de outros estados brasileiros, possui uma baixa densidade de estações pluviográficas, e as estações disponíveis geralmente possuem curtos períodos de monitoramento, ou com falhas, impossibilitando, assim, a determinação confiável das relações IDF. Nessas condições, métodos alternativos para a determinação de precipitações intensas são muitas vezes necessários.

Neste artigo foi apresentada uma análise da aplicabilidade do método proposto por Bell (1969) para a estimativa da precipitação intensa no RS em locais sem dados, e uma avaliação da incerteza no processo relacionada à estimativa da vazão de projeto com base nessa informação de precipitação, por meio do emprego do método racional em diferentes bacias de drenagem.

Os resultados mostraram que o método avaliado produziu resultados satisfatórios para a estimativa das chuvas intensas, visto que mesmo na pior situação verificada, para uma precipitação com período de recorrência de 2 anos, os erros médios obtidos na estimativa dessa informação foram de aproximadamente $10 \%$. Erros dessa magnitude estão dentro da ordem de incerteza da própria medição da precipitação em estações convencionais segundo Braga e Fernandes (2007), Pinheiro et al. (2014), Sieck, Bruges e Steiner (2007), WMO (WORLD..., 2008) entre outros.

As vazões determinadas a partir da precipitação estimada pelo método de Bell (1969), comparativamente àquelas determinadas a partir da precipitação intensa com origem em dados pluviográficos (sintetizadas em IDF ou relações entre durações) apresentaram variações próximas a 5\% em diferentes bacias típicas de microdrenagem urbana.

Os resultados mostraram que, além de ser uma boa alternativa para a estimativa das precipitações de projeto, a equação de Bell (1969) pode facilmente ser adaptada para utilização com dados de base diária, sem perda significativa de qualidade, 
servindo, portanto, como uma alternativa confiável para determinação das vazões de projeto na microdrenagem. Nesse sentido, o método permite determinar a precipitação intensa para qualquer período de recorrência e duração $(<2$ h), com base na precipitação com tempo de retorno de 10 anos e duração de 1 h do local. Para contornar problemas relacionados à ausência dessa informação em locais sem dados subdiários, a metodologia foi combinada com uma modificação, permitindo a estimativa da precipitação intensa com base em dados diários de precipitação, a qual é uma informação normalmente disponível (caso não disponível, pode ser obtida na Figura 5b).

Além da aplicabilidade para a estimativa de vazões de projeto em obras de microdrenagem, a metodologia pode ser igualmente aplicada na estimativa de precipitação para outros tipos de obras de engenharia, como dimensionamento de calhas, vertedores, bacias de detenção, entre outros.

Contudo, ressalta-se a importância do monitoramento dos dados hidrológicos, uma vez que a metodologia de Bell pode ser usada como uma alternativa para locais sem dados, porém nada substitui a necessidade de monitorar e atualizar os bancos de dados das variáveis hidrológicas.

\section{Referências}

ALLASIA, D.; VILLANUEVA, A. Custo da Incerteza na Macrodrenagem Urbana I: determinação dos parâmetros mais sensíveis na modelagem de macrodrenagem urbana. Revista Brasileira de Recursos Hídricos, v. 12, n. 1, p. 65-77, 2007.

BACK, A. J. Relações Entre Precipitações Intensas de Diferentes Durações Ocorridas no Município de Urussanga, SC. Revista Brasileira de Engenharia Agrícola e Ambiental, v. 13, n.2, p. 170-175, 2009.

BASSO, R. E. et al. Revisão das Isozonas de Chuvas intensas Do Brasil. Engenharia Sanitária Ambiental, v. 21, n. 4, p. 635-641, 2016.

BELL, F. C. Generalized Rainfall-DurationFrequency Relationships. Journal of the hydraulics division, v. 95, p. 311-327, 1969.

BELTRAME, L. F. S.; LANNA, A. E. L.; LOUZADA, J. A. S. Chuvas Intensas. Porto Alegre: IPH-UFRGS, 1991.
BERNARDI, E. S. et al. TRMM Rainfall

Estimative Coupled With Bell (1969)

Methodology for Extreme Rainfall

Characterization. Proceedings of the

International Association of Hydrological

Sciences, v. 369, p. 163-168, 2015.

BERTONI, J. C.; TUCCI, C. E. M. Precipitação. In: TUCCI, C. E. M. (Ed.). Hidrologia: Ciência e Aplicação. Porto Alegre: Editora da UFRGS/ABRH, 1993.

BIDONE, F.; TUCCI, C. E. M. Microdrenagem. In: TUCCI, C. E. M.; PORTO, R. L. L.; BARROS, M. T. Drenagem Urbana. Porto Alegre: Ed. Universidade/UFRGS/ABRH, 1995.

BRAGA, S.; FERNANDES, C. Performance de Sensores de Precipitação do Tipo “Tipping Bucket” (Báscula): um alerta para a ocorrência de erros. Revista Brasileira de Recursos Hídricos, v. 12, p. 197-204, 2007.

CHEN, C. L. Rainfall Intensity-DurationFrequency Formulas. Journal of Hydraulc Engineering, v. 109, n. 2, p. 1603-1621, 1983.

COMPANHIA DE PESQUISA DE RECURSOS MINERAIs. Atlas Pluviométrico do Brasil. Atualizado em novembro de 2011. 1 CD-ROM.

COUTINHO, L. F. et al. Modelos de Predição de Chuvas Intensas Para o Estado do Mato Grosso, Brasil. Ambiente \& Água - An Interdisciplinary Journal of Applied Science, v. 6, n. 3, p. 274290, 2011.

DEPARTAMENTO DE ÁGUAS E ENERGIA ELÉTRICA; COMPANHIA DE TECNOLOGIA DE SANEAMENTO AMBIENTAL. Drenagem Urbana. 2. ed. São Paulo, 1980.

DEUTSCHE HÄNGEGLEITERVERBAND. Drenagem da Cidade do Maputo: plano general. 1981.

DINGMAN, S. L. Physical Hydrology.

Hampshire: Prentice Hall, 2002.

ELTZ, F. L. F.; REICHERT, J. M.; CASSOL, E. A. Período de Retorno de Chuvas em Santa Maria, RS. Revista Brasileira de Ciência do Solo, v. 16, n. 2, p. 265-269, 1992.

ENDRENY, T. A.; IMBEAH, N. Generating Robust Rainfall Intensity-Duration-Frequency Estimates With Short-Record Satellite Data. Journal of Hydrology, v. 371, p. 182-191, 2009.

FALAGUASTA, L. N.; GENOVEZ, A. M. Equações de Chuvas Intensas Generalizadas Para os Estados de São Paulo e Paraná. Revista Brasileira de Recursos Hídricos, v. 8, n. 3, p. 169-176, 2003. 
FAVARETTO, J. R. Análise de Consistência e Regionalização das Precipitações Máximas Ocorridas no Rio Grande do Sul entre 19122014. Santa Maria, 2016. Dissertação (Mestrado em Engenharia Civil) - Programa de PósGraduação em Engenharia Civil, Universidade Federal de Santa Marina, Santa Maria, 2016.

FENSTERSEIFER, C. A. J. et al. Investigation of Urban-Induced Rainfall in Porto Alegre, Brazil Using TRMM Satellite Rainfall Estimation. IAHS-AISH Publication, v. 359, p 260-265, 2013.

FROEHLICH, D. C. Intermediate-DurationRainfall Intensity Equations. Journal of Hydraulic Engineering, v. 121, n. 10, p. 751-756, 1995.

GENOVEZ, A. M.; ZUFFO, A. C.; BORRI GENOVEZ, A. I. Relação Entre Chuvas Intensas de Diferente Duração e Avaliação das Equações de Chuvas Generalizadas. In: CONGRESSO LATINOAMERICANO DE HIDRÁULICA, 16., Santiago, 1994. Anais... Santiago: IAHR, 1994.

GENOVEZ, A.; ZUFFO, A. C. Chuvas Intensas no Estado de São Paulo: estudos existentes e análise comparativa. Revista Brasileira de Recursos Hídricos, v. 5, n. 3, p. 45-58, 2000.

GRINGORTEN, I. I. Modeling Conditional Probability. Journal of Applied Meteorology, v. 10, p. 646-657, 1970.

HERSHFIELD, D. M. Rainfall Frequency Atlas of the United States for Duration from 30 Minutes to 24 Hours and Return Periods from 1 to 100 Years. U. S. Department of Commerce, Washington, 1961.

HYAMS, D. G. CurveExpert: a comprehensive data analysis software system for Windows, Mac and Linux. 2013.

\section{INSTITUTO BRASILEIRO DE GEOGRAFIA E} ESTATÍSTICA. Anuário Estatístico do Brasil. Rio de Janeiro, 1997.

KIRPICH, T. P. Time of Concentration of Small Agricultural Watersheds. Journal of Civil Engineering, v. 10, n. 6, p. 362, 1940.

KOUTSOYIANNIS, D.; KOZONIS, D.; MANETAS, A. A Mathematical Framework for Studying Rainfall Intensity-Duration-Frequency Relationships. Journal of Hydrology, v. 206, p. 118-135, 1998.

KUICHLING, E. The Relation Between the Rainfall and the Discharge of Sewers in Populous Districts. Transactions ASCE, v. 20, p. 1-56, 1889.

\section{ORGANIZAÇÃO METEOROLÓGICA} MUNDIAL. Guide to Hydrological Practices. 6. ed. Genebra: OMM, 2008. N. 168.

PACHALY, R. et al. Análise da Incerteza Associada às Chuvas Intensas Obtidas das Isozonas Para Uso em Microdrenagem no Sul do Brasil. In: ENCONTRO NACIONAL DE ÁGUAS URBANAS, 11., Belo Horizonte, 2017. Anais... Belo Horizonte, 2017.

PINHEIRO, A. et al. Acurácia na Medição da Altura de Precipitação em Pluviômetros de Báscula. Revista de Estudos Ambientais, v. 1, n.7 p. 38-44, 2014.

REED, D. W.; FAULKNER, D. S.; STEWART, E. J. The FORGEX Method of Raifanll Growth Estimation II: description. Hydrology and Earth System Siences, v. 3, n. 2, p. 197-203, 1999.

REICH, B. M. Short Duration Rainfall Intensity Estimates and Other Design Aids for Regions of Sparse Data. Journal of Hydrology, v. 1, 1963.

RIGHETTO, A. M. Hidrologia e Recursos Hídricos. São Carlos: EESC/USP, 1998.

ROMAN, C. A. et al. Comparação Entre Chuvas Intensas Obtidas a Partir de IDF's e Pela Metodologia da Relação entre Durações. In: POLETO, C. (Org.). Águas Urbanas: volume 1. Porto Alegre: ABRH, 2015.

ROSSATO, M. S. Os Climas do Rio Grande do Sul: variabilidade, tendências e tipologia. Porto Alegre, 2011. $240 \mathrm{f}$. Tese (Doutorado em Geografia) - Escola de Geografia, Universidade Federal do Rio Grande do Sul, Porto Alegre, 2011.

SAMPAIO, M. V. et al. Equações de Chuvas Intensas na Região Hidrográfica do Guaíba, RS, Brasil. Tecnologia e Ciências Agropecuárias, João Pessoa, v. 5, p. 1-8, 2011.

SIECK, L. C.; BURGES, S. J.; STEINER, M. Challenges in Obtaining Reliable Measurements of Point Rainfall. Water Resources Research, v. 43, n. 1, 2007.

SILVEIRA, A. Provável Efeito Urbano nas Relações IDF das Chuvas de Porto Alegre.

Revista Brasileira de Recursos Hídricos, v. 2, n. 2, p. 93-107, 1997.

SILVEIRA, A.; BEMFICA, D.; GOLDENFUM, J. Análise da Aplicabilidade de Padrões de Chuva de Projeto a Porto Alegre. Revista Brasileira de Recursos Hídricos, v. 5, n. 4, p. 5-16, 2000.

SOLIMAN, M. M. Engineering Hydrology of Arid and Semi-Arid Regions. Boca Raton: CRC Press, 2010. 
STEPHENSON, D. J. Stormwater Hydrology and Drainage. Elsevier, 1981. v. 14.

TOWNSEND, D. Analyses of Intense Rainfall. Technical Report $\mathbf{n}^{\mathbf{0}}$ 2, UNDP/WMO project RAF/74/074, 1977.

TUCCI, C, E, M, Hidrologia: ciência e aplicação. Porto Alegre: Ed. da Universidade, 1993.

UEAHARA, K. et al. Pequenas Bacias

Hidrográficas do Estado de São Paulo: estudo de vazões médias e máximas. São Paulo: Escola Politécnica de São Paulo, 1980.

VIEIRA, D. B.; NETO, F. L.; SANTOS, R. P. dos. Relação Entre Intensidade, Duração e Frequência de Chuvas em Mococa, SP. Pesquisa

Agropecuária Brasileira, v. 33, n. 8, p. 12151220, 1998
WILD, J.; HALL, J. K. Aspects of hydrology in the province of North Sumatra, Indonesia.

Proceedings of the Institution of Civil

Engineers, v. 73, p. 85-108, 1982.

WORLD METEOROLOGICAL

ORGANIZATION. Guide to Meteorological Instruments and Methods of Observation. Genebra: WMO, 2008.

\section{Agradecimentos}

Os autores agradecem à Coordenação de Aperfeiçoamento de Pessoal de Nível Superior Brasil (Capes), ao CNPQ e à UFSM pelo suporte financeiro por meio de bolsa de estudo para esta pesquisa, e ressaltam que o presente trabalho foi realizado com apoio da Capes - Código de Financiamento 001.

Raviel Eurico Basso

Programa de Pós-Graduação em Engenharia Civil | Universidade Federal de Santa Maria | Av. Roraima, 1000, Cidade Universitária, Camobi | Santa Maria - RS - Brasil | CEP 97105-900 | Tel.: (55) 98142-3053 | E-mail: basso.raviel@gmail.com

\section{Daniel Gustavo Allasia}

Departamento de Engenharia Sanitária e Ambiental | Universidade Federal de Santa Maria | Tel.: (55) 3220-8423| E-mail: dallasia@gmail.com

\section{Rutinéia Tassi}

Departamento de Engenharia Sanitária e Ambiental | Universidade Federal de Santa Maria | E-mail: rutineia@gmail.com

\section{Revista Ambiente Construído}

Associação Nacional de Tecnologia do Ambiente Construído

Av. Osvaldo Aranha, 99 - 3o andar, Centro

Porto Alegre - RS - Brasil

CEP $90035-190$

Telefone: +55 (51) 3308-4084

Fax: +55 (51) 3308-4054

www. seer. ufrgs. br/ ambienteconstruido

E-mail: ambienteconstruido@ufrgs.br 